\title{
Elementos marxistas para la crítica de la ortodoxia neoclásica del comercio internacional
}

Roberto Góchez Sevilla

Departamento de Economía

UCA, San Salvador

RESUMEN: A partir de la década de los ochenta han recobrado predominancia las políticas de liberalización comercial, orientadas a alcanzar eventualmente un ideal "libre comercio". La ortodoxia neoclá-

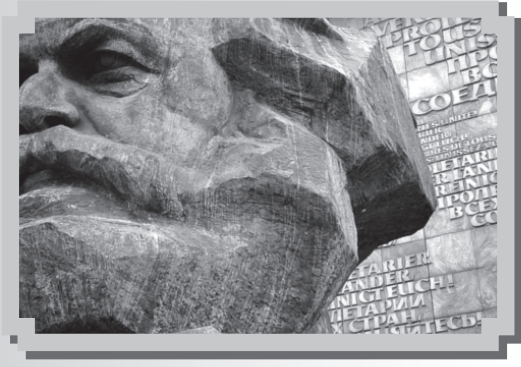
sica ciertamente puede admitir que existen problemas iniciales al darse el libre comercio, entendiéndolos como desajustes momentáneos para ciertos sectores. Algunos autores contemporáneos han contribuido a actualizar la teoría económica marxista. Los aportes de estos autores son importantes para construir un núcleo teórico, basado en la teoría del valor-trabajo de Marx, debido a las potencialidades que ofrece dicho marco analítico para captar las dinámicas reales actuales.

ABSTRACT: Since the decade of 80's, trade liberalization policies have become predominant. Such policies are aimed to reach eventually an ideal "free trade". Neo-Classic orthodoxy may admit that there are initial problems on free trade, assuming them as momentary problems for some sectors. Some contemporary authors have contributed to update the Marxist economic theory. Their contributions are important in order to build a theoretic core, based upon the Marxist theory of value-labor, due to the potentialities that such analytic frame offers to understand the real current dynamics. 


\section{Introducción}

$\Lambda$ partir de la década de los ochenta han recobrado predominancia las políticas de liberalización comercial, orientadas a alcanzar eventualmente un ideal "libre comercio", es decir un estado en donde el flujo comercial de bienes entre los países opere sin restricciones, principalmente de aquellas barreras provenientes de la acción de los gobiernos nacionales. En esa línea, los programas de ajuste estructural y estabilización promovidos por organismos internacionales y las principales potencias económicas han impulsado procesos unilaterales de liberalización comercial en las economías subdesarrolladas siguiendo el recetario del denominado "Consenso de Washington". También ha habido gobiernos que han diseñado sus propios programas de liberalización, removiendo barreras al comercio de manera considerable. El Salvador es un buen ejemplo de una mezcla de ambos tipos de procesos.

En los años noventa, las políticas liberalizadoras del comercio han sido impulsadas también por medio de los Tratados de Libre Comercio e Inversión, en el ámbito bilateral, y de las obligaciones derivadas de los acuerdos integrantes de la Organización Mundial del Comercio (OMC), en el ámbito multilateral. El contenido de esos acuerdos es amplio y trasciende el puro comercio de bienes, sin embargo en lo relativo a este último tienen una orientación librecambista. Hay que señalar no obstante esa orientación, el tipo de liberalización comercial que contienen los TLC y la misma OMC está sesgada principalmente hacia la eliminación de las barreras utilizadas por los países subdesarrollados, mientras deja intactas otras mas complejas utilizadas por los desarrollados.

Las políticas de "libre comercio" en general tienen una fuerte inspiración en la doctrina de las ventajas comparativas, que van desde los cimientos puestos por David Ricardo hasta su reformulación en el modelo Heckscher-OhlinSamuelson (HOS), que incorporan adicionalmente otros elementos como la competencia perfecta en un marco de equilibrio general. Esos modelos, con algunos aspectos monetarios añadidos posteriormente se constituyen en lo que se podría denominar el núcleo duro de la ortodoxia neoclásica en el ámbito del comercio internacional. Este núcleo, con su planteamiento de ventajas comparativas, se constituye en una de las fundamentaciones teóricas de las políticas librecambistas, por proveerle una visión armónica del comercio y la competencia internacional que vuelve prácticamente "indiscutible" en el plano teórico los beneficios del libre comercio para cualquier país que lo aplique. ${ }^{1}$

En la mayoría de manuales de economía internacional (Krugman et al., 2001; Appleyard et al., 2003) se puede apreciar que el núcleo duro 
neoclásico presenta en sus modelos teóricos una visión idealizada y armónica de los resultados del libre comercio en el largo plazo: a) Toda nación por atrasada e ineficiente que sea, una vez que aplique el libre comercio, podrá producir y exportar siempre algunos bienes, y por ende tendrá siempre al menos una opción para especializarse²; b) La especialización será tal que las naciones tenderán al equilibrio comercial; c) Al haber libre comercio, los países no sufrirán perdidas sistemáticas de competitividad, pues sus tipos de cambio real serán estacionarios (teoría de la paridad del poder de compra y sus ampliaciones); d) La especialización y el intercambio internacional resultante producirán un aumento del bienestar y/o del consumo, así como una asignación más eficiente de los factores productivos y el mantenimiento del pleno empleo en cada nación; e) Una producción mundial incrementada de bienes respecto a su autarquía; y f) En su extremo el comercio producirá una igualación de las retribuciones reales de los factores productivos entre países, permitiéndole mejorar al factor relativamente abundante.

No es extraño, como ha señalado Shaikh (2003: 2), que una interpretación ortodoxa de esa visión teórica concluya que la política comercial que mejor contribuye al desarrollo y al crecimiento es la liberalización comercial de los países, con el horizonte de alcanzar un ideal libre comercio, es decir la apertura total de los países al mer- cado mundial con la eliminación de todas las protecciones comerciales nacionales.

La ortodoxia neoclásica ciertamente puede concebir problemas iniciales al darse el libre comercio, ${ }^{3}$ como desajustes momentáneos (corto plazo) y efectos negativos para ciertos sectores. Sin embargo, considera que el propio mercado, si le deja funcionar libremente, con un tiempo suficiente para la reasignación de recursos correspondiente (a largo plazo) podrá superar esos problemas. Por otro lado, aquellos inicialmente afectados podrían mejorar su situación una vez sean compensadas sus pérdidas o cuando reorienten sus actividades en las ramas beneficiadas por el libre comercio, pues éste tiene la virtud, para el núcleo ortodoxo, que genera beneficios totales mayores a sus costos. De ahí que desde ésta visión lo más consecuente para el desarrollo sería acompañar la liberalización comercial con políticas económicas y sociales que buscarán facilitar el ajuste y atender los costos sociales mientras se cosechan los beneficios (Shaikh, 2003: 2), y por el contrario las políticas "proteccionistas" son consideradas como la opción más ineficiente y retrógrada.

Hay que señalar que en la economía convencional existen variantes de los modelos del núcleo duro, además de proliferar aproximaciones que incorporan "nuevos factores" y elementos de competencia imperfecta, éstas últimas que se han dado en Ilamar "Nuevas Teorías 
del Comercio Internacional (NTCI)" (Guerrero, 1995: 39). Los enfoques de competencia imperfecta suelen introducir variados aspectos que el núcleo duro no toma en cuenta, como por ejemplo: diferenciación de los productos; rendimientos crecientes de escala; empresas fijadoras de precios (monopolios u oligopolios), entre otros. Los resultados de los anteriores enfoques atenúan algunas de las conclusiones de la competencia perfecta, sobre la especialización, patrón de comercio y por lo tanto de los beneficios esperados. Sin embargo, algunos de estos modelos se presentan en muchas ocasiones como complementarios al de competencia perfecta o inscritos en su mismo marco general. ${ }^{4}$

El núcleo duro neoclásico no ha estado exento de críticas. Algunos estudios empíricos provenientes de la misma economía convencional han cuestionado su capacidad explicativa (Appleyard et al., 2003: 139-153). Aparte han surgido críticas contra la liberalización comercial de economistas provenientes de instituciones internacionales que han promovido esa agenda, ${ }^{5}$ siendo el ejemplo más notable posiblemente Joseph Stiglitz.

A pesar de las creciente críticas, de los variados modelos de competencia imperfecta "alternos" y de estudios empíricos que contradicen el núcleo duro de la ortodoxia neoclásica, parece que el mismo se mantiene intacto, tanto en sus pretensiones explicativas, como en su influencia ideológica y política: sigue siendo el que orienta la formación inicial de la casi totalidad de los economistas, al estar presente en la mayoría de libros de texto de economía internacional (Krugman et al., 2001; Appleyard, 2003; Ossa, 2002); ${ }^{6}$ y es aún dominante en la orientación librecambista de las políticas promovidas y aplicadas por organismos internacionales $y$ gobiernos nacionales.

Para muestra de su pretensión explicativa, a pesar de la evidencia empírica en contra, está la siguiente frase de Krugman et al. (2001:88): "Aunque el modelo HeckscherOhlin ha tenido menos éxito para explicar los patrones reales de comercio internacional del que cabría esperar, sigue siendo fundamental para entender los efectos del comercio, especialmente sus efectos en la distribución de la renta." Frente a esa aseveración valdría la siguiente pregunta: ¿Cómo puede un modelo que no encuentra respaldo empírico ayudar a comprender esa misma realidad que no capta?

La influencia política de la ortodoxia neoclásica se puede apreciar muy claramente en los discursos de personajes claves del sistema mundial de comercio, cuando asumen que la liberalización comercial tiene en sí misma e incondicionalmente un efecto positivo para todos los países involucrados. Por ejemplo, el anterior Director General de la OMC, Mike Moore, declaraba que "la liberalización del comercio genera empleo y crecimiento, y las personas que se benefician de los 
intercambios comerciales crean estabilidad, la consolidan y suscitan el entendimiento" (Moore, 2002).

Autores contemporáneos como A. Shaikh (1990), D. Guerrero (1995), G. Carchedi (1991) y R. Astarita (2006), entre otros, han contribuido a actualizar la teoría económica marxista. Destaca, sobre todo, su crítica al núcleo duro ortodoxo del comercio internacional, pero que también llega a alcanzar algunas de sus variantes de competencia imperfecta. Sus trabajos, con algunas notables variantes entre sí, no sólo se limitan a identificar y criticar la debilidad de los fundamentos últimos de donde extrae sus conclusiones la teoría convencional, sino que aportan bases para abordar el comercio internacional de una manera alterna. Los aportes de estos autores contemporáneos son importantes para construir un núcleo teórico, alterno al neoclásico, basado en la teoría del valor-trabajo de Marx, debido a las potencialidades que ofrece ese otro marco analítico para captar las dinámicas reales actuales.

Shaikh (1990) y Guerrero (1995) identifican dos aspectos centrales que están a la base de la visión armónica del libre comercio que tiene la teoría de la ventaja comparativa: a) el núcleo duro basa su predicción sobre el patrón de especialización del libre comercio y la conclusión sobre que es "incondicionalmente" beneficioso para todos los países involucrados, en la "ley de los costos comparativos". Esa ley a su vez depende de la existencia de algún mecanismo monetario automático (niveles de precios, salarios o tipos de cambio) que logren equilibrar la balanza comercial, incrementando los precios/costos monetarios en los países superavitarios y disminuyéndolos en los deficitarios. b) La corriente neoclásica introduce, con posterioridad a Ricardo, la concepción de competencia perfecta, con lo cual elimina del análisis todo vestigio de la competencia en su sentido de "batalla global" entre empresas por ganarle cuotas de mercado a sus competidoras. Consecuentemente las críticas de ambos autores van dirigidas sobre todo a mostrar la debilidad teórica y empírica de esos dos fundamentos del núcleo duro.

En el plano propositivo, Shaikh y Guerrero desarrollan una teoría de las ventajas competitivas clásico-marxista, y reivindican la superioridad teórica y empírica de ésta para comprender y explicar el comercio y la competencia a nivel internacional. Este núcleo alternativo al neoclásico, estaría basada en la teoría del valor-trabajo de Marx y tendría consecuentemente dos fundamentos: a) mecanismos monetarios que no son auto-correctores de los desequilibrios comerciales (oferta monetaria y tipos de cambio); b) una teoría dinámica de la competencia, que la considera en su sentido real, es decir como "una batalla global" o "intensa rivalidad de la empresas". Interpretado desde la perspectiva de esos autores críticos, el que no 
se haya llevado a cabo la especialización y los beneficios predichos por las ventajas comparativas, no se debe en última instancia a que las economías desarrolladas impongan unas condiciones desventajosas a las subdesarrolladas o a alguna "imperfección" del mundo real. Más bien, es el propio funcionamiento del capitalismo, ${ }^{7}$ con el proceso de competencia real a nivel internacional y sus mecanismos monetarios subyacentes, el que reproduce la desigualdad entre países y al interior de ellos, que ciertamente puede ser agravado o atenuado por esos otros factores. Desde esta óptica, es perfectamente compatible el hecho que con la liberalización comercial unos países, y particularmente sus empresas, ganen sistemáticamente cuotas de mercado y otros las pier- dan. Los saldos comerciales de los países tienen una estrecha relación, si bien complejizada, con el proceso de competencia real que llevan las empresas.

En este breve artículo se sintetizan principalmente algunas de las ideas de A. Shaikh (1990) y D. Guerrero (1995), dirigidas a develar los dos fundamentos últimos del análisis del comercio internacional del núcleo ortodoxo, y a destacar el papel central que juegan estos en la visión armónica del comercio internacional que de ahí deriva esta corriente. Se abordan brevemente los elementos que ambos identifican que debe contener una teoría alterna a la neoclásica, sin embargo este punto se espera desarrollar más detalladamente en una futura publicación.

\section{La ley de costos comparativos y mecanismos monetarios}

A Shaikh (1990: 155-157) ha señalado que la ley oculta detrás de la ventaja comparativa es la de los costos comparativos, que resulta central y crucial para la conclusión armonicista del comercio internacional que presentan las ventajas comparativas, en la cual juegan un papel clave los mecanismos monetarios -incluyendo los tipos de cambio- subyacentes. Esa "ley" está presente tanto en la versión básica de la ventaja comparativa de David Ricardo, como en la presentación neoclásica del modelo HOS.
La ley de costos comparativos plantea básicamente que los términos de intercambio de los países se ajustarán automáticamente al dejar operar a las fuerzas del mercado, para alcanzar y mantener el equilibrio comercial, y que esos nuevos términos de intercambio representan una mejora respecto a una situación de autarquía para todos los países. En el caso de que un país sea superavitario, los términos de intercambio se moverán para encarecer los precios monetarios (en moneda común) de su bienes relativos al otro, mientras que en el caso del deficitario lo harán 
para abaratar los precios monetarios (en moneda común de su bienes), movimiento que continuará hasta alcanzar el equilibrio comercial, lo que presupone que todos los países tendrán posibilidades de exportar algunos bienes. Los términos de intercambio se ajustan pues para favorecer por igual a todos los países que participan del libre comercio, en particular protegiendo al débil.

Como se aprecia de lo anterior, la ley de los costos comparativos llevada al extremo es la que le permite a la teoría ortodoxa considerar que por muy atrasados productivamente que sean los países, o por muy grandes y amplias que sean sus desventajas absolutas en costos monetarios y productividad iniciales, automáticamente —si se cumplen ciertas condiciones mínimas de partida y luego de un proceso de ajuste-, se verán beneficiados una vez que opere el libre comercio, pues siempre podrán exportar algunos bienes, intercambiarlos por otros que dejarán de producir, y consecuentemente beneficiarse del comercio.

Por ejemplo, si un país A tiene una tecnología atrasada en todos sus sectores de producción, que lo lleva a tener mayores costos monetarios en moneda común (precios absolutos) en todos los bienes respecto de otro país $B$, el funcionamiento de esa ley le permitirá que con el libre comercio $-y$ sin necesidad de cambios productivos (tecnología) pueda adquirir ventajas de precios/ costos en algunos de ellos, porque se habrán abaratado en términos monetarios, aquellos en los que su desventaja era menor, y consecuentemente podrá exportarlos a cambio de otros bienes. Desde la ventaja comparativa (Krugman, 2001: 24) incluso los países desarrollados con altos salarios no tendrían que temer de la competencia con países de remuneraciones bajas, pues la misma ley impediría que los segundos países se apropiaran de todas las ramas productivas.

La acción de la ley de costos comparativos no necesita suponer medidas explícitas de política económica, más que la liberalización comercial inicial, ni ninguna modernización productiva posterior de las empresas pues la operación de la misma estaría garantizada por mecanismos automáticos monetarios — dirigidos a su vez por la ley de la oferta y la demanda-. Cuando mucho, sería algo relevante (Shaikh, 1990: 4) para la ventaja comparativa, que el movimiento de los términos de intercambio se muevan para eliminar los desequilibrios de balanza comercial.

Guerrero (1995: 33) señala que para Ricardo aunque las ventajas de productividad podían ser persistentes a nivel internacional, los desequilibrios comerciales no podían serlo pues asumía la operación del mecanismo flujo especie de Hume: salida de oro para el país deficitario y reducción de sus precios/costos/salarios por un lado, y por el otro lado, entrada de oro al país superavitario, con el consiguiente 
incremento de los precios/costos/ salarios, mecanismos que mejoraría la competitividad de sus bienes para el primero y la deteriorarían para el segundo, y que sólo se detendría al haber equilibrio comercial. El bien en el que un país tuviera inicialmente los menores costos relativos sería en el que tendría su ventaja comparativa, pues al operar el mecanismo monetario sería en el que adquiriría ventaja de costos monetarios, sin importar cuán grande fuera la desventaja inicial de costos monetarios. En resumen el mecanismo monetario flujo-especie es el que permitía, para Ricardo, convertir la ventaja comparativa "potencial" en "efectiva" (Guerrero, 1995: 33) y daba vigencia a la ley de costos comparativos.

La creencia en el mecanismo de flujo-especie de Hume fue lo que llevó a Ricardo a plantear: que la teoría del valor-trabajo, que operaba a nivel interno, no era válida para determinar las relaciones de cambio en el comercial internacional; la superioridad de la ventaja comparativa (basada en costos relativos o costos intersectoriales) sobre la ventaja absoluta (basada en costos absolutos intrasectoriales).

D. Salvatore (1999: 37) señala que Haberler (en 1936) reformuló la teoría de la ventaja comparativa de Ricardo, introduciendo el concepto de costo de oportunidad, que hace referencia a "la cantidad de una segunda mercancía a la que se debe renunciar para liberar los recursos estrictamente necesarios para producir una unidad adicional de la primera mercancía". Al introducir ese concepto el núcleo duro puede mostrar las conclusiones centrales de las ventajas comparativas ricardianas con una economía de trueque (Ossa Scaglia, 2002: 17), lo que la libera de la teoría del valor-trabajo, de la dependencia de la teoría cuantitativa del dinero clásica (Hume) y de tener que hacer referencia al dinero. La consideración del trueque no quiere decir en sentido estricto que suponga su existencia real, sino que más bien es una simplificación analítica que posibilita a la economía convencional dividir el análisis real del monetario, y se lo puede permitir precisamente por su posterior tratamiento del dinero como simple medio de cambio y la neutralidad que se asume tiene sobre las variables reales en el largo plazo. $^{8}$

Las versiones neoclásicas modernas de la ventaja comparativa (modelo HOS y el ricardiano de costos de oportunidad) asumen la ley de costos comparativos, pues suponen que los términos de intercambio - de trueque en este caso- se ajustan para equilibrar el comercio (Shaikh, 1990: 160). Como es trueque, y lo que se compara es el costo de oportunidad, no necesita hacer referencia explícita a los mecanismos monetarios necesarios para que se cumpla. Sin embargo una vez que se introduce en la discusión los costos monetarios o una economía monetaria, el núcleo duro necesita de alguna teoría que ponga 
en vigencia la ley de costos comparativos en el sentido esperado, pues de lo contrario tendría serias dificultades para explicar como un país capitalista que tiene empresas que producen inicialmente más caros (monetariamente) todos los bienes, puede luego exportar alguno de ellos. Según Shaikh, todo mecanismo monetario (nivel de precios o tipo de cambio) que tenga por efecto reducir los precios/costos en el país deficitario y aumentarlos en el país superavitario, hasta equilibrar el comercio internacional, le sirve a la corriente neoclásica para justificar su asunción de la ley de costos comparativos. La teoría neoclásica puede tomar entre una variedad de opciones de mecanismos "modernos" (Shaikh, 1990: 160 y 184186): "la versión de saldos reales en efectivo de la teoría cuantitativa"; "la determinación keynesiana de los precios por medio del nivel salarial"; y tipos de cambio totalmente flexibles, que se mueven hasta corregir los desequilibrios de balanza comercial. ${ }^{9}$

Resumiendo pues, para el núcleo duro lo relevante para beneficiarse y especializarse al haber libre comercio es tener los menores costos relativos o de oportunidad o intersectoriales, lo que no requiere la existencia previa de ventajas absoluta de productividad ni de costos (monetarios) en algún bien. ${ }^{10}$ La ventaja comparativa para un país, así entendida, podría incluir aquellos sectores en los cuales una nación posea las mayores ventajas absolutas - productividad/costos monetarios-, para el caso de una nación que lo tenga, como también aquellos en los que su desventaja absoluta fuera menor, para el caso de un país que tuviera desventaja de productividad/costos monetarios en todos los sectores. Es por eso que Krugman et al. (2001: 36) afirman que "la proposición de que el comercio es beneficioso es incondicional. Es decir no se requiere que un país sea 'competitivo' o que el comercio sea "justo".

Una vez que una economía se encuentra en libre comercio, enfoques como la Paridad del Poder de Compra (PPA) Absoluta y Relativa, y otras versiones desarrolladas de estos, le son funcionales al planteamiento neoclásico para plantear que los tipos de cambio real se mantendrán estacionarios en un valor constante. Eso significa, que en el largo plazo y en presencia de libre comercio, los países involucrados no pueden ganar ni perder competitividad sistemáticamente en el largo plazo. No hay pues posibilidades que ningún país pierda con el libre comercio, al inicio y con el tiempo.

Shaikh (2003: 5) remarca la poca evidencia empírica del supuesto que los términos de intercambio se ajustan para eliminar los desequilibrios comerciales o que se mantengan estacionarios. Así señala que: 
"el problema es que esta proposición nunca ha sido empíricamente verdadera: ni en el mundo desarrollado ni en el mundo subdesarrollado, ni con tasas de cambio fijas ni con tasas de cambio flexibles. Por el contrario, los desequilibrios persistentes son el sine qua non del comercio internacional. Esto no es ninguna sorpresa para quienes están familiarizados con la historia de los países en desarrollo. Pero es igualmente cierto para el mundo desarrollado."

A partir de la dependencia de la ventaja comparativa de algún mecanismos monetario, se puede plantear el siguiente cuestionamiento: ¿Qué ocurre si los términos de intercambio no se mueven en el sentido esperado para eliminar el desequilibrio comercial?, y ¿qué ocurre si se mueven incluso contrario a lo esperado? Shaikh (1990) y Guerrero (1995), destacan que los mecanismos monetarios que verdaderamente operan no son autocorrectores de los desequilibrios de balanza comercial como los supone la ventaja comparativa. Para ambos autores si se parte de una teoría del dinero y sus funciones basada en Marx, las conclusiones son muy diferentes a las esperadas por el núcleo duro neoclásico, pues los mecanismos monetarios automáticos que funcionan no lo hacen respondiendo a la necesidad de eliminar desequilibrios comerciales. Ciertamente en algunas circunstancias pueden darse movimientos de algunas variables (apreciaciones/depreciaciones o caída/incremento de salarios) en el sentido que identifica la ventaja comparativa producto de un desequilibrio comercial, sin embargo no necesariamente lo hacen siguiendo sistemáticamente la lógica de eliminar los desequilibrios comerciales.

Para Marx, el dinero no sólo cumple la función de ser medio de cambio, sino también la de atesoramiento, lo que le permitió, entre otras cosas, alejarse de la teoría cuantitativa del dinero clásica (Hume) y de la concepción de trueque. Para algunos autores (Sardoni, 2004) la función de atesoramiento del dinero de Marx supone: un rechazo a la idea que toda oferta crea su propia demanda (ley de Say); da cabida a la posibilidad de crisis de sobreproducción y economías operando normalmente por debajo del pleno empleo. Para Marx (Shaikh, 1990: 188-208), en una economía capitalista, que necesariamente es monetaria, son las tasas de interés las que se ajustan en primera instancia a desequilibrios monetarios, dentro de los cuales estarían los originados por los saldos de balanza comercial. Al haber déficit o superávit comercial, y consecuentemente variaciones derivadas de la oferta monetaria, son las tasas de interés las que se ajustarán pero no para eliminar esos desequilibrios, sino cuando mucho para cubrirlos por los movimientos contrarios que se generarán en los flujos de capital. ${ }^{11}$ 
La línea argumental de los dos autores mencionados, es que en caso de darse el "libre comercio", una economía con desventajas absolutas iniciales de costos en la gran mayoría de sus sectores, experimentará un déficit comercial global y en el intercambio de la gran mayoría de bienes, mientras tanto la otra economía, con ventajas absolutas de costos, verá aparecer un superávit. El país deficitario comercialmente, al perder reservas, reducirá la oferta monetaria y verá aumentar sus tasas de interés. Esos diferenciales de las tasas de interés generarán eventualmente incentivos para el endeudamiento del primero respecto al segundo. En algún nivel el crecimiento de los flujos de capital pueden ser suficientes para cubrir, sin eliminar, el monto del déficit comercial en el país con desventajas productivas. Mientras tanto el otro país con una oferta de bienes expandida, podrán salir flujos de capital en la forma de préstamos al otro país que le permitirán compensar en algún punto el superávit comercial. No obstante esta situación de "equilibrio", que se puede dar en la balanza de pagos será temporal, pues el endeudamiento genera la obligación de pagar intereses futuros, abriendo la posibilidad de crisis de pagos eventualmente. La inversión extranjera directa, otros flujos de capital y transferencias corrientes también puede servir para financiar el mantenimiento del desequilibrio comercial. ${ }^{12}$ En resumen, los flujos de capital pueden permitir una situación comercial deficitaria o supe- ravitaria secular e incremental de un país, influyendo cuando mucho en el "equilibrio" a nivel de la balanza de pagos, el cual será inestable por la naturaleza misma que tiene -rezago o superioridad productiva de los países-.

Si a todo lo anterior se agrega que los tipos de cambio real, siguen según Shaikh (1999) una ruta determinada por el proceso real de competencia y no por el equilibrio comercial, las cosas son aun más difíciles para hacer una previsión sobre lo "incondicionalmente" beneficioso que es el libre comercio y sobre la reversión automática de una situación inicial comercialmente desventajosa para el país con rezago competitivo. Con una trayectoria de los tipos de cambio real marcada por la evolución de la competencia a nivel internacional, la teoría de la paridad de compra difícilmente puede cumplirse como norma, y por el contrario las apreciaciones o depreciaciones reales sistemáticas de los mismos serán la constante. ${ }^{13}$

Así los dos autores mencionados reivindican la necesidad que una teoría alternativa que parta de la ventaja absoluta de Smith, entendida ésta como realmente la planteaba dicho autor, como una ventaja de costos monetarios intrasectoriales. Los fundamentos puestos por Marx, permiten desarrollar una aproximación de este tipo, pues dan cabida a mecanismos monetarios subyacentes que no son correctores a los desequilibrios comerciales. 
omo destaca el mismo Shaikh (1990: 159) y Guerrero (1995: 39), la vertiente neoclásica no solo retoma la ley de costos comparativos y la reformula con costos de oportunidad, sino que la enmarca en la competencia perfecta, con equilibrio general, asumiendo la constancia y uniformidad de la tecnología entre las ramas similares de los países, lo que da origen al modelo predominante de HOS.

El modelo de competencia perfecta en general, se basa en los siguientes supuestos: gran cantidad de vendedores y compradores; homogeneidad de los productos; libre entrada y salida de empresas del mercado; el objetivo de las empresas es la maximización de los beneficios; ausencia de control estatal; movilidad perfecta de los factores de producción; conocimiento perfecto (Koutsoyiannis, 2002: 165).

En un entorno de competencia perfecta con los supuestos descritos, las empresas, que suelen ser de rendimientos constantes de escala y marginales decrecientes, maximizan su beneficio buscando ajustar el nivel de producción en el corto plazo modificando únicamente los factores variables. En el largo plazo hacen lo mismo, pero pueden modificar todos los factores incluyendo el tamaño de la planta - aunque no buscan modificar la tecnología para reducir costos o mejorar sus productos-.
En el largo plazo pueden entrar y salir empresas de cada industria, orientándose por los beneficios positivos (entran) y negativos (salen), lo que hace que el beneficio - una especie de ganancia "extraordinaria" sobre los costos - desaparezca en todas las industrias. Todos los factores son retribuidos por el valor de su productividad marginal (capital y trabajo) en todas las industrias, es decir por el valor de su contribución marginal a la producción. Como se suele asumir empresas "representativas" por rama, eso significa que todas las firmas en una industria tienen la misma estructura de costos ligada a idéntica tecnología - función de producción-, que cuando mucho pueden variar en el corto plazo por la escala de producción (Guerrero, 1995: 63-72). Todo eso significa que el capital utilizado recibirá la misma tasa de retribución (r) en todas las empresas (iguales) de todas las industrias.

Los supuestos de la competencia perfecta dan origen a empresas/ productores que asumen/creen/actúan como entes incapaces de modificar los precios de mercado, y de hecho se supone que sus acciones no tienen la capacidad de influir en los mismos. Las empresas pueden vender toda su producción a los precios vigentes sin afectarlos, es decir son "tomadoras de precios" o "precio aceptantes" (sic). No es extraño que los mismos autores 
de manuales de microeconomía convencional como Varian (1999: 387) reconozcan que el marco de competencia perfecta se aleja del sentido cotidiano de competencia como intensa rivalidad, pues en ese marco las empresas sólo se preocupan por decidir sobre la cantidad a producir. Es más, para Koutsoyiannis (2002: 165), "en la teoría, la competencia perfecta implica ausencia de rivalidad".${ }^{14}$

Pocas veces se destaca que la empresa/productor "precio aceptante", en realidad toma pasivamente los precios de mercado, pues "ni le preocupa ni quiere influir sobre los mismos" (Guerrero, 1995: 57). Esa pasividad se refleja en particular que las firmas no buscan cambiar su tecnología — representada por su función de producción - para reducir sus costos o mejorar sus productos, respecto a sus competidores, elemento clave en la competencia real. Las empresas sólo deciden poner en el mercado dócilmente el nivel de producto que maximiza su beneficio. En resumen, en las propias palabras de Shaikh (1990: 88):

"la firma es, pues, no solamente pacífica por naturaleza, también es impotente. De un plumazo las características centrales de guerra entre firmas - la intención de pelear y la capacidad de hacer daño- son eliminadas por presunción. En la competencia perfecta, en otras palabras, no tiene cabida la competencia de capitales".

Algunos de los modelos de competencia imperfecta asumen ciertos supuestos similares a la ventaja comparativa y competencia perfecta, que los lleva a mantener las conclusiones armónicas del libre comercio del núcleo duro, si bien atenuadas, y una relación hasta cierto punto complementaria con el núcleo duro. La pasividad descrita, sobre todo por cambiar su tecnología para reducir costos o mejorar sus productos, es el elemento que señala Guerrero (1995: 18-19 y 5759) que hermana a la competencia perfecta, de empresas "precio aceptantes", con algunos modelos de la imperfecta de precio determinantes, en un sólo enfoque o paradigma estático de competencia. El común denominador entre las empresas de competencia perfecta e muchas de imperfecta es que todas son costo aceptante, en un marco de constancia y uniformidad tecnológica. ${ }^{15}$

Es debido a esa concepción de "imperfecta", que algunos de los modelos que se enmarcan ahí aceptarían implícitamente que el mundo ideal funcionaría como lo predice el núcleo duro de darse las condiciones perfectas, pero en un aparente mayor realismo, consideran la existencia de fallas de mercado o imperfecciones del mundo real que llevan a desviaciones respecto 
de lo predicho por los modelos basados en la perfecta. ${ }^{16}$ Así el alcance de sus críticas muchas veces puede ser a matizar las conclusiones favorables al libre comercio de ese núcleo duro, poniendo el acento en la corrección que el Estado debería hacer de los fallos de mercado e imperfecciones que presenta el mundo real, para que se acerque más al funcionamiento ideal que predice la ortodoxia.

Una competencia "perfecta" tal como la descrita, tiene los siguientes resultados teóricos, según algunas hipótesis extras: el intercambio permite llegar a un óptimo de Pareto, es decir un equilibrio que permite maximizar el beneficio y/o utilidad a todos (empresas y consumidores) en el cual no es posible que nadie mejore sin desmejorar a otros; se alcanza el pleno empleo y se da el vaciado de todos los mercados — sin posibilidad para que exista una sobreproducción generalizada-; ese equilibrio es único y estable ante perturbaciones, y cambiará sólo si cambian condiciones de oferta o demanda. Como dice Bowles et al (1985: 117) "en el modelo neoclási$\mathrm{co}$, una vez alcanzado el equilibrio, nada puede cambiar hasta que no intervenga un factor procedente del exterior, o exógeno", además "el equilibrio se alcanza todos los días y la competencia por sí sola apenas fomenta el cambio". La competencia perfecta, está asociada más a un estado de equilibrio -precios de equilibrio y vaciado de los mercados- que a un proceso dinámico de lucha de las unidades de capital. El mayor o menor grado de competencia desde la economía convencional está asociado fundamentalmente al número de empresas y la posibilidad que salgan y entren, dejando de lado el aspecto central del cambio tecnológico.

En el ámbito internacional, el núcleo neoclásico (HOS) asume competencia perfecta, con empresas representativas de una rama en cada país, que tienen la misma tecnología - uniformidad- con sus similares de los otros países y se mantiene sin cambio - constancia- (Ossa, 2002: 99). La uniformidad tecnológica que plantea el modelo HOS es una diferencia respecto al ricardiano, que partía de tecnologías diferentes entre las mismas ramas de los países. El modelo HOS basa las diferencias de costos relativos previas al comercio en la abundancia relativa de factores, descartando básicamente la posibilidad de ventajas de productividad al asumir la misma función de producción entre países (Shaikh, 1990: 159)

La adopción del supuesto de competencia perfecta en el ámbito del comercio internacional, le permite al núcleo duro neoclásico en primer lugar asumir la plena utilización de recursos y pleno empleo, antes y después de que opere el comercio a cada país. El supuesto de pleno empleo a su vez le es necesario para: utilizar el concepto de costo de oportunidad, que en caso de haber desocupación no tendría sentido; asumir que hay mejoras 
de bienestar reales o potenciales, que serían difíciles de sostener si el libre comercio generara desempleo (Shaikh, 2003: 3). En segundo lugar, la "concepción" de competencia perfecta le permite eliminar totalmente la competencia en su sentido de intensa rivalidad a nivel internacional, es decir deja descartado que las empresas de un país busquen y consigan ganar sistemáticamente cuotas de mercado y/o eliminen a sus rivales de la otra nación.

Los supuestos más restrictivos de uniformidad y constancia de la tecnológica en cada rama a nivel internacional, le permite concluir que los factores productivos (capital y trabajo) van a igualar su tasa de retribución ahora internacionalmente, y que eso no se modificará en el tiempo. ${ }^{17}$ Por ejemplo, el capital recibirá la misma tasa de pago (r) no sólo en todas las empresas de una industria y en todas las industrias de un país, sino que ahora en todos los países. Otro tanto ocurrirá con la tasa salarial de los trabajadores (w). Para el caso nacional, la igualdad del pago a los factores se daría con libre movilidad de los mismos, sin embargo la teoría neoclásica concluye que, sin necesidad de libre movilidad internacional de factores, eso mismo se puede dar a través del libre comercio entre países.

En resumen, el modelo HOS, utilizando la competencia perfecta, uniformidad y constancia tecnológi- ca y la ley de costos comparativos, difícilmente puede concluir otra cosa que al darse el libre comercio: cada país producirá algunos bienes (aquellos intensivos en los factores relativamente abundantes); exportará una cantidad de bienes suficiente para cubrir un valor similar de importaciones (equilibrio comercial); la especialización producirá un aumento del bienestar en cada país; aumentará el consumo en cada país respecto a lo que podía permitirse en autarquía; habrá una asignación más eficiente de los factores productivos; se mantiene el pleno empleo; una mayor producción mundial de bienes respecto a autarquía; una igualación de la retribuciones de los factores productivos entre países, permitiéndole mejorar en particular al factor relativamente abundante.

Del cuestionamiento hecho hasta ahora de la competencia perfecta, surgiría la pregunta, ¿hay un cuerpo teórico en la economía que sea alterno al neoclásico?. La respuesta que dan Shaikh y Guerrero en sus respectivos trabajos es sí. Ambos señalan que la línea teórica que va desde los clásicos hasta la reformulación hecha por Marx de la economía política clásica destaca la competencia como un proceso turbulento más parecido a una guerra, más que a un estado armonioso y estable. Shaikh (1990:84) lo expresa elocuentemente cuando dice: 
"el movimiento del capital de una industria a otra corresponde a la determinación del territorio (sitio) de batalla; el desarrollo y adopción de tecnología corresponde al desarrollo y adopción de las armas de guerra (la carrera armamentista); y la competencia de una firma contra otra corresponde a la batalla misma."

Diego Guerrero (1995: 17), por otro, lado señala a la competencia como:

"una batalla global que comienza en el ámbito de la inversión y la acumulación de capital desde el punto de vista técnico y organizativo de la producción, para extenderse finalmente a la esfera comercial de las estrategias adecuadas para ganar cuotas de mercado a costa de los rivales".

La visión dinámica de la competencia, sostenida por Guerrero y Shaikh contrasta con el enfoque estático y pasivo de la competencia perfecta, y se ajusta más al funcionamiento real de las economías capitalistas.

Para Guerrero (1995) y Shaikh (1990), el desarrollo de la teoría del valor-trabajo de Marx, que va desde el concepto de valores pasando por la formación de los precios de producción, contiene una teoría de la competencia de carácter dinámico, susceptible de ser desarrollada. Esa teoría de la competencia contiene dos niveles o formas, que se llevan simultáneamente, pero que se pueden diferenciar para propósitos explicativos:

a) Competencia intrasectorial: Cuando Marx aborda el valor social de una mercancía, está haciendo referencia a este primer nivel. Los productores de una rama (productora de un bien homogéneo) compiten por producir a menores costos una determinada mercancía, de la competencia surge un precio único para cada mercancía, que dichos autores denomina precio directo (que corresponde a lo que Marx Ilama valor social o valor de mercado). Las empresas tienen diferente estructura tecnológica y consecuentemente diferentes costos, pero, como se forma un solo precio para un bien homogéneo, las firmas de una misma rama obtendrán una tasa de rentabilidad diferenciada. En este nivel de competencia, juega un papel determinante la mecanización que introducen las empresas, para abaratar sus costos y mejorar sus productos, pero también toda ventaja natural o producida que pueda permitirles alguna ventaja sobre los competidores. Serán aquellas empresas con los menores costos las que se apropiarán de una mayor tasa de beneficio y 
la de mayores costos, las que se apropiarán de una menor. Esa rentabilidad diferenciada es el incentivo que hace que constantemente ocurran cambios, pues las empresas aunque pudieran tomar los precios como datos, buscarán siempre echar mano a todo aquello que les posibilite obtener ventajas de costos y/o ganar cuotas de mercado a sus rivales.

b) Competencia intersectorial: $\mathrm{El}$ capital busca la mayor retribución para su capital, lo que genera movimientos del mismo entre ramas, buscando aquellas con mayor rentabilidad y saliendo de las que tienen menos. Esto produce una tendencia hacia la nivelación de las tasas de ganancia del capital entre ramas (llamada tasa media de ganancia). Los precios que surgen de ese proceso son llamados por Marx de producción, que son diferentes para bienes distintos pero que incorporan una tasa media de ganancia. Esta segunda tendencia — competencia intersectorial— se lleva a cabo

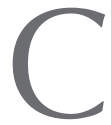

on lo expuesto anteriormente queda claro que del núcleo duro neoclásico sólo puede resultar una visión armónica e idealizada del libre comercio y la "competencia" internacional. La ley de costos comparativos planteada por Ricardo, deja fuera toda posibi- simultáneamente a la primera —intrasectorial—, lo que significa que no todas las empresas de una rama obtendrán esa tasa media. Las empresas por debajo del promedio sectorial de eficiencia obtendrán una tasa de rentabilidad menor que la media, y las que están por arriba podrán obtener una mayor. Ese proceso de nivelación de la tasa de ganancia se refiere a un proceso y no tanto a un estado: "una tendencia permanente a la igualación sectorial, pero una tendencia que se realiza en medio de la permanente desigual real de dichas tasas sectoriales.." (Guerrero, 1997: 67)

De nuevo para los dos autores (Shaikh y Guerrero), una teoría de la competencia que capte las dinámicas reales puede ser mejor desarrollada en el marco teórico clásicomarxista. La concepción armonicista de la competencia perfecta, que utiliza el núcleo duro, encuentra su superación crítica en el desarrollo de la teoría del valor-trabajo de Marx, y la teoría subyacente de la competencia dinámica.

\section{Reflexiones finales}

lidad de que un país, por ineficiente que sea, pierda con el libre comercio. Por si lo anterior fuera poco, y aunque no es necesario suponer la constancia y uniformidad tecnológica $^{18}$ ni adoptar la competencia perfecta, como lo muestra Ricardo, el núcleo duro neoclásico lo hace 
de manera tal que elimina totalmente la competencia nacional e internacional, en su sentido de "intensa rivalidad" o "batalla global". Esa concepción plantea una especie de proceso en que los países convergirán en un mundo armónico y estable a través del libre comercio, media vez transcurra un tiempo para los ajustes necesarios. Si eventualmente hay algún cambio real, como tamaño de la población, tecnología o gustos de los consumidores, habrá nuevos ajustes que llevarán eventualmente a nuevos equilibrios de características similares.

Consecuentemente la concepción armónica del núcleo duro le lleva al mismo a derivar conclusiones "normativas" como las de aplicar y promover la liberalización comercial general y en última instancia buscar el libre comercio. Una lectura igualmente dogmática y mecánica de los modelos del núcleo duro aplicaría incluso la liberalización comercial total y unilateral en presencia de distorsiones como subsidios o aranceles de los otros países, pues al final de cuentas serían éstos los irracionales que se estarían negando a recibir los beneficios potenciales del intercambio internacional una vez que se especializaran.

En este punto se hace necesario señalar algo importante, que recuerda Shaikh (1990: 83) y Escobar (2008), sobre el uso por parte de todas las teorías económicas y sus modelos del recurso de la abstracción. Todo proceso de abstracción teórica lleva indudablemente a enfatizar algunos aspectos y a obviar otros, sin embargo ese proceso como señala Shaikh (1990:83) debe ser "tipificación, la extracción de la 'más simple caracterización' de algún aspecto de la realidad", lo que ocurre con la teoría neoclásica, y particularmente válido para su núcleo duro del comercio internacional, es que "las abstracciones fundamentales tienden a ser idealizaciones, no tipificaciones" (Shaikh, 1990:83).

La importancia del párrafo anterior, es que ayuda a remarcar que la crítica que se hace al núcleo duro del comercio internacional no se refiera al uso del recurso de la abstracción, sino a la idealización que realiza éste sobre el comercio internacional por abstraerse de elementos fundamentales del mundo real. En esa idealización juegan un papel central los dos elementos que han sido identificados en los dos numerales previos. Precisamente la importancia ideológica que tienen las conclusiones del núcleo duro son: su fundamentación a las políticas librecambistas; reproducir una visión mitificada de la realidad, sobre todo en los economistas, pues los manuales representan al modelo HOS como una primera aproximación del comercio internacional.

El trabajo de Shaikh y Guerrero ha sido amplio en dirección de desarrollar elementos teóricos y evidencia empírica para fundamentar el núcleo de una teoría de las ventajas competitivas clásico-marxista, como una 
contribución para la comprensión de las realidades actuales del comercio internacional y para la superación de la visión idealizada que hace el núcleo duro ortodoxo. Ambos autores señalan la necesidad de desarrollar una aproximación al comercio internacional a partir de Marx, por lo inacabado de su obra, basada en un trinomio: la teoría del valor-trabajo, mecanismos monetarios no auto-correctores de los desequilibrios comer- ciales y una teoría de la competencia dinámica. La tarea emprendida por los autores arriba mencionados es importante, pues permite construir un núcleo teórico básico, alternativo al neoclásico, que además de captar mejor dinámicas reales de la competencia internacional, posibilita una base para desarrollos posteriores que integren diferentes problemáticas actuales relacionadas al comercio internacional.

\section{Bibliografía}

- Appleyard, D. y A. Field. (2003). Economía Internacional. Cuarta Edición. Bogotá. McGraw-Hill Interamericana.

- Astarita, R. (2006). Valor, mercado mundial y globalización. Buenos Aires. Ediciones Kaicron.

- Bowles, S. y Richard Edwards. (1985). Introducción a la economía: competencia, autoritarismo y cambio en las economías capitalistas. Madrid. Alianza Universidad Textos. 1985.

- Carchedi, G. (1991). Frontiers of Political Economy. London New York. Verso.

- Escobar, B. (2008). "Sobre lo "Científico", lo "Ético", lo "Factico", Ensayando una Crítica a la Teoría Económica y Neoclásica". Revista Realidad. No. 114, Octubre-diciembre 2007. pp 555-578.
- Guerrero, D. (1997). Historia del Pensamiento Económico Heterodoxo. Madrid. Editorial Trotta.

- Guerrero, D. (1995). Competitividad: teoría y política. Barcelona. Ariel Economía.

- Krugman, P. R. y M. Obstfeld. (2001). Economía Internacional. Teoría y política. Quinta edición. Madrid. Pearson Educación.

- Koutsoyiannis. A. (2002). Microeconomía Moderna. Primera reimpresión. Buenos Aires. Amorrortu/editores.

- Moore, M. (2002). Discurso Pronunciado en Conferencia de la OMC de Ministros de Comercio para Europa Central y Sudoriental. 11 y 12 de Julio 2002. [En línea]. Zagreb. Disponible en: http://www.wto.org/spanish/ news_s/spmm_s/spmm87_s.htm [Consultado el día 13 de enero de 2008] 
- Ossa Scaglia, F. (2002), EConomía Internacional. Aspectos Reales. Segunda edición. Bogotá. Alfaomega Colombiana y Ediciones Universidad Católica de Chile.

- Pugel, T. A. (2004). Economía Internacional. Decimosegunda edición. Madrid. Mcgraw-Hill.

- Salvatore, D. (1999). Economía Internacional. Sexta edición. México. Prentice Hall.

- Sardoni, C. (2004). Marx y Keynes: la crítica a la ley de Say. En Miren Etxezarreta (coord). Seminario de Economía Crítica de Taifa. Crítica a la Economía Ortodoxa. Balleterra (Barcelona). Servei de Publicacions y Universidad Autónoma de Barcelona.

- Shaikh, A. (2003). La Globalización y el Mito del Libre Comercio. Versión en español. New York. New School for Social Research University. [En línea]. Disponible en: http://homepage. newschool.edu/ AShaikh/ [Consultado el día 13 de enero de 2008]

NOTAS

1 El uso del término ortodoxia neoclásica no tiene ningún sentido peyorativo bien pretende remarcar que la visión favorable al libre comercio se basa fundamentalmente en el abordaje que la teoría neoclásica hace del comercio internacional a través de esos modelos. Ciertamente existen infinidad de modelos - y variantes
- Shaikh, A. (1999). Real Exchange Rates and the International Mobility of Capital.

- Shaikh, A. y R. Antonopoulos. (1998). Explaining Long Term Exchange Rate Behavior in the United Stated and Japan. New York. Working Paper No. 250. The Jerome Levy Economic Institute of Bard College. [En línea]. Disponible en: http://www.levy.org/vauth. aspx?auth=246 [Consultado el día 18 de Enero de 2008].

- Varian, H. R. (1999). Microeconomía Intermedia. Un Enfoque Actual. Quinta edición. Barcelona. Antoni Bosch.

- Working Paper No. 265, The Jerome Levy Economics Institute of Bard College. [En línea]. Disponible en: http://homepage.newschool.edu/ AShaikh/ [Consultado el día 18 de Enero de 2008].

. (1991). Valor, Acumulación y Crisis. Ensayos de Economía Política. Segunda edición. Bogota. Tercer Mundo Editores.

de los mismos- del comercio internacional provenientes de la corriente neoclásica, pero los predominantes en cuanto a la prescripción de políticas librecambistas siguen siendo el HOS y algunas de sus variantes cercanas.

2 Incluso en el caso extremo de que una determinada nación produzca inicialmente todos los bienes con 
mayores costos absolutos (monetarios) por su mayor ineficiencia en ellos respecto al resto del mundo, una vez operan los mecanismos del "mercado" podrá adquirir ventajas en al menos uno de ellos, y por ende podrá producir e intercambiarlo, mejorando su bienestar.

3 En particular, el modelo de factores específicos o algunas consideraciones sobre los efectos redistributivos sobre las curvas de utilidad social le permite considerar la posibilidad que no todos se beneficien del libre comercio, pero rápidamente son dejadas de lado en los libros de texto con supuestos adicionales.

4 Por ejemplo, el modelo de competencia monopolística (Krugman et al., 2003: 136-143) es un caso ilustrativo de la visión favorable al libre comercio aun en competencia imperfecta, y a pesar de resultados que podrían cuestionar las conclusiones del modelo HOS. Krugman destaca como un mercado más grande y rendimientos crecientes de escala puede permitir beneficios por la mayor variedad de productos y su menor costo, si bien reconoce que en ese nuevo marco no se puede concluir acerca del patrón de comercio o sobre la ubicación de las empresas. Sin embargo, esos nuevos elementos no son utilizados por ese autor para cuestionar que las bondades supuestas del libre comercio las reciban efectivamente todos los países involucrados. Por el contrario, Krugman hace una presentación flexible de una especie equilibrio general y comercial, que combina flujos de comercio explicados por ventaja comparativa y otros explicados por el comercio de productos diferenciados.
5 Shaikh (1990:161-4) señala que algunas de las críticas que provienen de la ortodoxia o economía convencional (neoclásica o keynesiana) como del marxismo, no critican los propios fundamentos de la ley, sino aspectos secundarios de la misma.

$6 \quad$ No resulta extraño entender que el autor de uno de los libros de texto más utilizados de economía internacional se exprese en los siguientes términos: "el papel tradicional de los economistas es apoyar firmemente el libre comercio, destacando las ganancias generales; los que resultan perjudicados normalmente tienen pocos problemas para hacer oír sus quejas.” (Krugman et al., 2001:59).

7 Se podría agregar que tampoco se originaría por los salarios bajos de la periferia ni por el tipo de productos en que se especializan estos.

8 Sandoni (2004: 187) señala que la concepción que el dinero se demanda únicamente como medio de circulación es conceptualmente idéntica a suponer trueque y se pueden obtener los mismos resultados analíticos: la oferta crea su propia demanda (ley de Say) y pleno empleo.

$9 \quad$ Shaikh (1990: 185) señala que en el enfoque de saldos reales se asume que un país deficitario, reduce la oferta monetaria, lo cual llevará a un decremento de precios y salarios; el de salarios, asume que un déficit generará desempleo, una caída de salarios y una caída de precios, mientras que el superavitario tendrá un aumento de empleo, mayores salarios y aumento de precios; con tipos de cambio flexible, un país con déficit comercial sufriría una depreciación y el otro una apreciación de su moneda. 


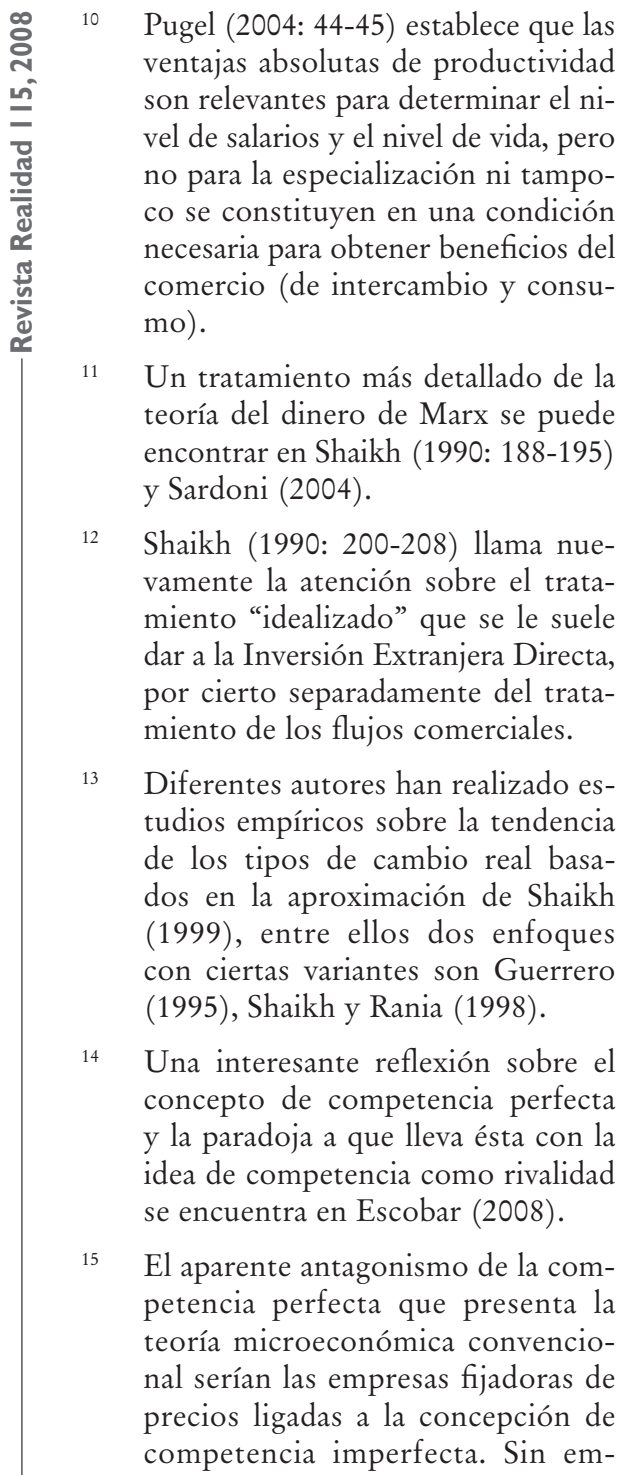

bargo, como ya se mencionó, para Guerrero (1998: 57-58) esa es una falsa dicotomía, pues muchos de los modelos de competencia imperfecta tiene en común con la perfecta que ofrecen una visión estática de la competencia: las empresas, sean precio aceptantes o determinantes, son costo aceptantes.

16 Un ejemplo notable es la presentación de Krugman et al. (2003: 141-143) de la competencia monopolística, y la "combinación” (no formal) que hace de sus conclusiones con las del núcleo HOS.

17 Algunas veces se introduce el cambio tecnológico ex-post, pero en ese caso si se mantiene que supuesto del modelo HOS sobre que la tecnología sea la misma en cada rama en ambos países implícitamente requeriría que se asuma que todas las empresas pueden adoptar fácilmente la mejor tecnología del momento.

Appleyard (2003) presenta brevemente un modelo de dos países, dos factores y dos bienes. En dicho modelo, cada país tiene ventajas en la tecnología, respecto a un bien distinto, pero están dotados de factores y preferencias similares gráficamente. Así, ese concluye que se crean las condiciones para el comercio y permite que ambos países se beneficien, si bien implicaría que no se igualen internacionalmente las remuneraciones de los factores productivos. 